\title{
Statistical Optimization of Lipid Extraction from Wastewater Scum Sludge and Saponifiable Lipids Composition Analysis
}

\author{
Samir N. Hag Ibrahim ${ }^{1,2}$ \\ ${ }^{1}$ Biology Department, Faculty of Science and Arts, Taibah University, Al-Ula, Saudi Arabia \\ ${ }^{2}$ Department of Environmental Science and Technology, Faculty of Science and Technology, Al Neelian University, Khartoum, Sudan
}

Email address:

sfadul@taibahu.edu.sa

\section{To cite this article:}

Samir N. Hag Ibrahim. Statistical Optimization of Lipid Extraction from Wastewater Scum Sludge and Saponifiable Lipids Composition Analysis. Science Journal of Energy Engineering. Vol. 5, No. 2, 2017, pp. 48-57. doi: 10.11648/j.sjee.20170502.12

Received: March 31, 2017; Accepted: April 11, 2017; Published: October 18, 2017

\begin{abstract}
In the present study, Design of Experiment (DoE) as a statistical method was adopted for optimizing conditions for lipid extraction from scum sludge. Four different extraction variables were investigated: methanol to hexane ratio (\%), solvent to sludge ratio $(\mathrm{ml} / \mathrm{g})$, temperature $\left({ }^{\circ} \mathrm{C}\right)$, and extraction time $(\mathrm{h})$. During the optimization process, saponifiable lipids (SLs) content of the extracted lipid was analyzed. Screening experiments revealed that methanol to hexane ratio (X1), solvents to sludge ratio (X2) and temperature (X3) showed a significant effect on $\mathrm{Y}_{\text {lipid }}(\mathrm{p}<0.05)$. Lower methanol to hexane ratio and higher solvent to sludge ratio showed the highest positive effect on lipid yield $\left(\mathrm{Y}_{\text {lipid }}\right)$. No significant effect on extraction time on $Y_{\text {lipid }}$ was observed. The positive relationship between lower methanol to hexane ratio and the amount of lipid extracted can be attributed to the presence of higher amounts of neutral lipids in scum sludge. According to Box-Behnken design and Response surface method (RSM), the maximum lipid extraction yield ( $\left.\mathrm{Y}_{\text {lipid }}\right)$ predicted through numerical optimized conditions by the model for highest desirability (0.995) was $29.614 \%$ at methanol to hexane ratio (\%) of $42 \%$, solvent to sludge ratio (v/wt) of $51 \mathrm{ml} / \mathrm{g}$, temperature at $87^{\circ} \mathrm{C}$ for extraction time of 6 hours. The FAMEs yield produced from ex-situ acid-catalyzed esterification/transesterification of the methanol-hexane co-solvent extracted lipid ranged between $7.9-9.3 \%$ (wt/wt) based on sludge weight. Fatty acid profile of FAMEs was found to be was found to be dominated by Oleic acid methyl ester (C18: 1) followed by methyl Palmitate (C16: 1) representing 39.4\% and 24.3\% of FAMEs composition respectively. The correlation analysis of extraction variables and FEMAs yield revealed that solvent to sludge ratio $(\mathrm{ml} / \mathrm{g})$ has the highest positive significant correlation with FAMEs yield (p-value $<0.05$ ). However, methanol to hexane ratio $(\mathrm{X} 1)$ and temperature (X3) were inversely correlated with FAMEs yield.
\end{abstract}

Keywords: Scum Sludge, Lipid, Box-Behnken Design, Response Surface Method (RSM), FEMAs

\section{Introduction}

The global social expansion and technological development is highly dependent on fossil fuel as a driving force. However, besides fossil fuel is considered as a nonrenewable resource which is a limiting factor for global financial as we all technological development, fossil fuel consumption adds lots of environmental burdens and impacts severely on the global ambient temperature. In addition, many countries in developing world spend more than $20 \%$ of its national income for importing fossil fuel which is economically hindering their development. As a consequence, there is an international trend towards alternative renewable energy sources allocation $[1,2]$. Biodiesel is one of the renewable energy alternatives that attracted an increased attention globally has been used as fuel in diesel engines and heating systems for over 25 years [3-9]. Biodiesel has many advantages over fossil fuels-drived diesel such as better emission profile, renewability, lower aromatic and sulfur content and availability [10-12]. However, biodiesel production is still commercial limited due to the high-cost production costs. Since the 1990s, food-grade oil raw materials used and a major source for biodiesel production [13]. Vegetable-based biodiesel, feedstock 
accounts more than $70 \%$ of biodiesel production costs which making it uncompetitive with petroleum-derived biodiesel [14]. Therefore it's a high time to look for low-cost and nonedible feedstock alternatives.

Municipal sludge lipids are gaining more attention nowadays as a promising source for lipid which can lower biodiesel cost production and make it more profitable for industries. As municipal sewage sludge is a waste, formed during the treatment of wastewater, it is a possible alternative source of lipids for the production of biodiesel, consequently lowering the wastewater treatment plant (WWTP) operation costs [15-20]. Research has shown that the lipids contained in sewage sludge are a potential feedstock for biodiesel mainly and comprised of fatty acids predominantly in the range of $\mathrm{C} 10$ to $\mathrm{C} 18$, which are excellent for the production of biodiesel [20, 21].

Chemically, biodiesel fuels are fatty acid methyl or ethyl esters (FAME) that is produced via esterification and transesterification of various lipid sources in the presence of a base, acid, enzyme or solid catalyst. Lipid extraction is the first step for biodiesel production from wastewater treatment plant sludge. At present, several methods are available for lipid extraction from biological materials. Most of these methods use organic solvents, usually in mixtures [4, 22-25]. Extraction of lipids from sludge can be influenced by many variables such as the type of sludge, type, and the amount of solvent, extraction time, temperature, stirring rate, type of microorganisms present in the sludge, etc. Although several researchers have demonstrated the lipid extraction from wastewater sludge, the effects of different parameters and their optimization have not been investigated.

Municipal sludge lipids are gaining more attention nowadays as promising lipid source which can make biodiesel production more profitable. As municipal sewage sludge is a waste, formed during the treatment of wastewater, it is a possible alternative source of lipids for the production of biodiesel, consequently lowering the wastewater treatment plant (WWTP) operation costs [15-20]. However, there are still different technical and economical constraints required to be solved before scaling-up into industrial scale can be reached. Compared to microalgae, wastewater sludge has more potentiality for scaling-up due to the technical aspects (such as biomass cultivation, collection, and separation), which are already settled; also the availability of biomass in a large amount as the process by-product. However, there are key aspects should be considered first to ensure successful scaling-up, these includes 1) an efficient lipid extraction process with high saponifiable lipids (SLs) content; 2) lowering the cost of sludge drying process and even more preferable to efficiently produce biodiesel from wet sludge.

Lipids extracted from municipal sludge differ quantitatively as well as qualitatively according to the type of microorganisms in the sludge; type of wastewater being treated; operational condition of the wastewater treatment plant; and type of sludge "primary, secondary or scum sludge." It has been demonstrated that municipal sludge is largely comprised of fatty acids "i.e. NLs", predominantly in the range of $\mathrm{C} 10$ to $\mathrm{C} 18$ which are excellent for biodiesel production $[15,23,25,26]$. However, bacterial species present in the sludge have a wider range of lipid fractions, due to the fact that bacteria are either assimilate lipids from the wastewater or synthesise them in situ and store them intracellularly as NSLs "e.g. triacylglycerides, TAGs"; or as USLs "e.g. waxes esters, WEs; or polyhydroxyalkanoates, PHAs". Therefore, optimal extraction process to ensure maximum extraction of SLs for biodiesel production and to minimize co-extraction USLs from municipal sludge sources is required.

Lipid extraction is the first step for biodiesel production from wastewater treatment plant sludge. At present, several methods are available for lipid extraction from biological materials. Most of these methods use organic solvents, usually in mixtures [4, 22-25]. Extraction of lipids from sludge may be influenced by many variables such as the type of sludge, type and amount of solvent, extraction time, temperature, stirring rate, type of microorganisms present in the sludge, etc. Several authors investigated lipid extraction for biodiesel production from primary sludge [16, 21, 24, 27, $28,28-31]$, secondary sludge [15, 18, 24, 27, 32]. Only a few studies gave attention to scum sludge as a source of lipids for biodiesel production [33-35]. Scum sludge is a floatable material usually skimmed from the surface of primary and secondary settling tanks in wastewater treatment plants. Scum sludge has a negative impact on the operation of wastewater treatment plant since it can clog treatment systems, causing sludge flotation, a significant amount of grease and oil in scum can deteriorate aerobic and anaerobic treatment processes, reduce sludge dewatering [36]. Therefore, scum sludge has to be removed from the beginning of wastewater treatment process by using grit chambers. Scum sludge is either partially-recycled, partially co-digested or landfilled. The later option increases the operational cost of the facility. Based on the report of the U. S. EPA's Office of Solid Waste, approximate 1-3 billion gallons of waste grease, oil and fats are produced every year in the 30 metropolitan areas in the United States [37]

In the present study, lipid extraction from scum sludge for biodiesel production was investigated. Lipid extraction from scum sludge was optimized using Design of Experiment (DoE) approach through manipulating four extraction parameters which have been reported to play a significant role in the extraction process. The Four extraction parameters investigated in the current study were: 1) methanol to hexane ratio $(\%)(\mathrm{X} 1) ; 2)$ solvent to sludge ratio $(\mathrm{X} 2) ; 3)$ temperature (X3); 4) and extraction time (X4). Besides, the quality of the extracted lipid was characterized regarding saponifiable lipids (SLs) content and FEMAs profile.

\section{Materials and Methods}

\subsection{Research Approach}

The current research aims to optimize lipid extraction from scum sludge for the purpose of biodiesel production using 
Design of Experiment (DoE) as a statistical approach. The study started with samples collection and preparation for lipid extraction. Lipid extraction from scum sludge was conducted using methanol: hexane co-solvent. Figure 1 shows the experimental approach layout adopted in the current study. Screening lipid extraction experiments were followed by optimization process and lipid composition analysis for saponifiable lipids (SLs) composition.

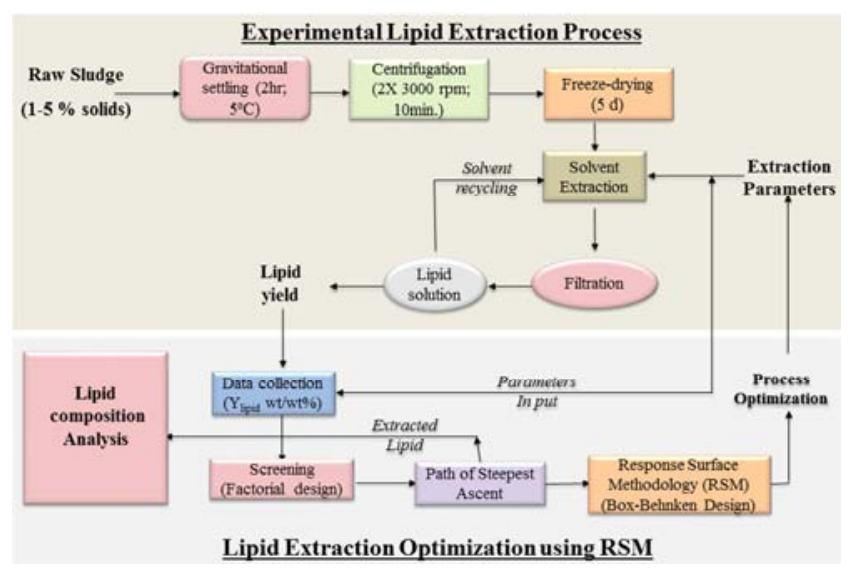

Figure 1. Schematic representation of experimental lipid extraction process and extraction optimization steps using DoE.

\subsection{Sludge Sample Collection and Preparation}

The scum sludge used in this study was collected from screening chambers of municipal wastewater treatment located in Madinah, KSA, in Alkhaleel area north of the city. The treatment plant is a conventional activated sludge system (without tertiary treatment) and has a design capacity of $129.000 \mathrm{~m}^{3} /$ d. In 2001 , the WWTP was upgraded to a total capacity of $240.000 \mathrm{~m}^{3} / \mathrm{d}$ and implemented a new extended aeration activated sludge tank followed by sand filtration

$$
\mathrm{Y}_{\text {lipid }}=(\text { Residual weight }(\mathrm{mg}))
$$

Table 1. The experimental variables, their low, high and center point levels for lipid extraction from scum sludge.

\begin{tabular}{llll}
\hline Variables & Low (-1) & High (+1) & $\begin{array}{l}\text { Center point } \\
(\mathbf{0})\end{array}$ \\
\hline $\mathrm{X} 1$ : Methanol to Hexane $(\%)$ & 40 & 80 & 60 \\
X2: Solvent to Sludge ratio $(\mathrm{ml} / \mathrm{g})$ & 10 & 40 & 25 \\
X3: Temperature $\left({ }^{\circ} \mathrm{C}\right)$ & 30 & 80 & 55 \\
X4: Extraction Time $(\mathrm{h})$ & 1 & 6 & 3.5 \\
\hline
\end{tabular}

\subsection{The Design of Experiment (DoE) for Lipid Extraction from Scum Sludge}

The Design of Experiment (DoE) approach allows investigating the influence of different factors on a given process, through conducting a minimal number of experiments [35]. DoE as a statistical method has been widely used and successfully implemented for different bioprocess optimization purposes [22, 29, 35-39]. Process optimization used in the present study was conducted in four main steps: 1) independent variables selection and their variation ranges and defining dependent (response) system.

The scum sludge samples were collected in plastic bottles and kept on ice during transportation to the laboratory. Scum samples were sieved with $<2 \mathrm{~mm}$ screening mesh and concentrated by gravitational settling at $5^{\circ} \mathrm{C}$ for 12 hours. After settling the supernatant was discarded and the settled sludge was subjected to two rounds of centrifugation at 3000 rpm for $10 \mathrm{~min}$ for further dewatering. The thickened sludge samples were then frozen at $-20^{\circ} \mathrm{C}$ and freeze-dried for 5 days. The freeze-dried samples stored in freezer till further use.

\subsection{Lipid Extraction}

Lipid extraction was conducted using different extraction variables as listed in Table 1, namely, methanol to hexane ratio (\%), solvents to sludge ratio ( $\mathrm{ml}$ solvents/g dried sludge), temperature $\left({ }^{\circ} \mathrm{C}\right)$ and extraction time (h). Lipid extraction from scum sludge was carried out according to the method described by Wang et al. [32]. Tthe mixture of $5 \mathrm{~g}$ scum sludge and solvents (as defined in Table 1) was placed in a condenser-attached $500 \mathrm{ml}$ Erlenmeyer flask for sequential extraction. After extraction, the resulting mixture was filtered using Buchner funnel, Whatman filter paper No. 1 and water aspirator to remove the remaining solvents. The filtrates were further concentrated using a rotatory evaporator at $40^{\circ} \mathrm{C}$ and dried to a constant mass in a vacuum desiccator. The resulting lipid was weighed, and the yield of extracted lipid was then determined and expressed as a percentage of grams extractable lipid per gram dry sludge [7]. All solvents (Methanol and n-Hexane) were HPLC-grade and purchased from Fisher Scientific (Atlanta, USA). The yield of extracted lipid was calculated according to the following formula:

\section{$($ Sludge solid weight $(\mathrm{mg})) \times 100$}

variable(s); 2) data screening for determining the main effect independent variables on response variable; 3) conducting the path of steepest ascent to direct the experimental outputs towards the optimum; 4) carrying out the statistically designed experiments in a randomized order and estimating the coefficients and the mathematical model. Different statistical methods were applied to investigate and optimize the extracted lipid content (yield, $\mathrm{Y}_{\text {lipid }}$ ), these methods included: $2 \mathrm{k}$ factorial screening design to determine the main effects, the path for steepest ascent, Box-Behnken design and Response Surface Method (RSM) for modeling the process and optimization. All statistical analysis was performed using the JMP@software (Version 13.1.0, SAS Institute, Cary, NC, USA).

\subsection{1. $2^{k}$ Factorial Screening Design}

Screening the main effects of variables is the first step in the optimization process, in which the effect magnitude of every independent variable was estimated. $2^{\mathrm{k}}$ factorial design as a screening method is a well-established statistical 
technique for screening the main effects of the independent variables based on first order model [22]:

$$
\mathrm{Y}_{\text {lipid }}=\beta_{0}+\sum \beta_{\mathrm{i}} \mathrm{X}_{\mathrm{i}}+\varepsilon
$$

Where $\mathrm{Y}$ is the response variable ( $\left.\mathrm{Y}_{\text {lipid }} \mathrm{wt} / \mathrm{wt} \%\right), \beta 0$ is the model intercept, $\beta_{i}$ is the linear coefficient, $X_{i}$ is the magnitude of the independent variable, and $\varepsilon$ is the error factor.

According to $2^{\mathrm{k}}$ factorial screening design, four extraction variables were screened using full factorial analysis with 16 runs with two levels design: low (-1) and high (+1). Table 2 represents the screening design matrix illustrating the levels of parameters used. The main effect of each variable was estimated based on the average difference between the high and low levels measurements. All experimental measurements for the screening experiments were performed in triplicates and averaged. Analysis of variance (ANOVA) was conducted to evaluate variables with a significant effect on lipid yield from the extraction process (response variable, $\left.\mathrm{Y}_{\text {lipid}}\right)$.

\subsubsection{The Path of Steepest Ascent}

The path of steepest ascent method was conducted to determine the direction of the increases in response variable ( $\left.\mathrm{Y}_{\text {lipid }}\right)$. The direction of response increase was determined based on the results obtained from the screening step, which identified the significant variables. A step-wise steepest ascent was performed started from the variable levels that produced the maximum lipid yield in the screening results, and ended when a near optimal/plateau point was reached. The results from the steepest ascent step were further used for further process optimization using response surface method (RSM).

\subsubsection{Box-Behnken Design for Lipids Extraction Optimization}

For optimizing the lipid extraction from scum sludge, Box-Behnken design and Response surface methodology (RSM) were conducted [29, 39]. Box-Behnken design (BBD) was performed to optimize the most significant variables identified by factorial screening design step with three center points. Table 3 shows the experimental design matrix used for Box-Behnken design. The Response Surface Method (RSM) was thus applied to visualize the experimental region. Predicting the optimal conditions can be estimated using the following second-order polynomial equation:

$$
\mathrm{Y}_{\text {lipid }}=\beta_{0}+\sum \beta_{\mathrm{i}} \mathrm{Xi}+\sum \beta_{\mathrm{ii}} \mathrm{X}_{\mathrm{i} 2}+\sum \beta_{\mathrm{ij}} \mathrm{X}_{\mathrm{i}} \mathrm{X}_{\mathrm{j}}+\varepsilon
$$

Where $\mathrm{Y}_{\text {lipid }}$ is the predicted response variable (amount of extracted lipid from scum sludge), $\beta_{0}, \beta_{\mathrm{i}}, \beta_{\mathrm{ii}}$ and $\beta_{\mathrm{ij}}$ are the regression coefficients of intercepts, linear quadratic and interaction terms respectively. While $X_{i}$ and $X_{j}$ are the independent variables and $\varepsilon$ is the error term.

Measurements for optimization experiments were performed in triplicates and averaged except for the center points. The quality of the fit of the polynomial model equation was determined using regression coefficient $\left(\mathrm{R}^{2}\right)$ and Adjusted $\mathrm{R}^{2}$. The significance the regression coefficients were checked using F-test.

Table 2. $2^{k}$ factorial screening design matrix and the response variable (Ylipid $)$ from scum sludge.

\begin{tabular}{llllll}
\hline Run order & $\mathbf{X 1}$ & $\mathbf{X 2}$ & $\mathbf{X 3}$ & $\mathbf{X} 4$ & $\mathbf{Y}_{\text {lipid }}(\mathbf{w t} / \mathbf{w t} \%)$ \\
\hline 1 & - & + & - & - & 27.4 \\
2 & + & - & - & - & 19.8 \\
3 & - & - & + & - & 27.4 \\
4 & + & - & + & + & 23.4 \\
5 & - & - & - & - & 24.4 \\
6 & - & + & + & + & 29.21 \\
7 & + & + & + & + & 25.7 \\
8 & + & - & + & - & 23.3 \\
9 & - & + & - & + & 27.9 \\
10 & + & + & - & - & 21.8 \\
11 & + & + & - & + & 22.1 \\
12 & - & + & + & - & 29.1 \\
13 & + & - & - & + & 20.1 \\
14 & + & + & + & - & 24.7 \\
15 & - & - & - & + & 24.8 \\
16 & - & - & + & + & 27.6 \\
\hline
\end{tabular}

\subsection{Quantifying and Profiling SLs of Extracted Lipid}

Lipids extracted from the steepest ascent step (section 2.3.2) were used for SLs composition analysis. SLs are the lipids that can be transformed into biodiesel (FAMEs) through esterification process. Lipids, in general, can be classified into two major categories based on the polarity of the head molecules; those are: 1) polar lipids (PLs); and 2) Neutral lipids (NLs). Polar lipids (PLs) can further be classified into phospholipids and glycolipid which are also considered as saponifiable lipids (SLs) because they contain fatty acids. While Neutral lipids (NLs) comprise Neutral Saponifiable Lipids (NSLs) "e.g. acylglycerols and free fatty acids (FFA)"; and Unsaponifiable Lipids (USLs) "e.g. hydrocarbons, sterols, and waxes" [26].

SLs of extracted lipid were converted into FAMEs (biodiesel) through esterification/transesterification in the presence of an acid catalyst $\left(\mathrm{H}_{2} \mathrm{SO}_{4}\right)$ according to the method describes by Dufreche et al. [7]. Twenty milligrams of lipids was dissolved in $1 \mathrm{~mL}$ of hexane containing and added to a vial with $2 \mathrm{~mL}$ of $1 \%$ sulfuric acid in methanol. The vial was then capped and heated overnight at $50^{\circ} \mathrm{C}$. Then, a $5 \mathrm{~mL}$ aliquot of $5 \% \mathrm{NaCl}$ in water was added, and the FAMEs were extracted with hexane, with vortexing the vial between extractions to provide efficient mixing. The hexane phase was washed with $2 \%$ sodium bicarbonate and dried over sodium sulfate.

The FAMEs produced by transesterification were analyzed using gas chromatography (GC) (HP 4890 D, HewlettPackard company, Wilmington, DE, USA) equipped with a capillary column and FID detector (Supelcowax: $30 \times 0.53$ $\mathrm{mm} ; 0.25 \mu \mathrm{m}$, Agilent Technologies, USA). The carrier gas was nitrogen, with a flow rate of $1 \mathrm{~mL}$ min-1 and sample injection volume was $1 \mu \mathrm{L}$, and injection split ratio 100: 1 . The temperatures of the injector, the detector, and the oven were held at 230,250 and $210^{\circ} \mathrm{C}$, respectively. The results of 
GC-FID were used to calculate the amount of saponifiable (transesterifiable / esterifiable lipids to FAMEs) material in the extracted lipid fraction and hence the maximum yield of biodiesel (FAMEs) that could be produced. The correlation between FAMEs and extraction conditions were assessed using principal component analysis (PCA) using XLSTAT@software (Addinsoft, Paris, France).

\section{Results and Discussions}

\subsection{Factorial Design for Screening of Variables}

The screening designs experiments and the resulting $\mathrm{Y}_{\text {lipid }}$ of 16 runs are presented in Table 2, where levels of parameters and statistics are shown in Table 3. The analysis of variance (ANOVA) indicated that the resulting model fit for $Y_{\text {lipid }}$ was highly significant $(p=<0.0001)$, besides, the model lack of fit value was $>0.05(\mathrm{p}=0.5371)$ and $\mathrm{R}^{2}=0.98$ confirming that the model fits the experimental data and explains $98 \%$ of the data variability.

According to Table 2, methanol to hexane ratio (X1), solvents to sludge ratio (X2) and temperature (X3) showed a significant effect on $\mathrm{Y}_{\text {lipid }}(\mathrm{p}<0.05)$. In particular, lower methanol to hexane ratio and higher solvent to sludge ratio showed the highest positive effect on lipid extraction. The positive relationship between lower methanol to hexane ratio and the amount of lipid extracted can be attributed to the presence of higher amounts of neutral lipids in scum sludge. Similar results were recorded by Wang et al. [32], who reported highest percentage of hexane (20: 60: 20) generated the largest lipid amount from scum sludge due to the dominance of neutral lipid in scum sludge which is easily extracted by hexane (as non-polar solvent). For extraction time, small or no effect was observed on $Y_{\text {lipid }}$ within the examined range $(p>0.05)$. Therefore, extraction time variable (X4) was excluded from the steepest ascent test. All studied variable showed a positive effect on $\mathrm{Y}_{\text {lipid }}$ as demonstrated by the sign of the $\beta$ coefficient, except for methanol to hexane ratio (X1) which showed a negative correlation as indicated in Table 3. The highest $Y_{\text {lipid }}$ was recorded at 40: 40: 80: 6 for X1, $\mathrm{X} 2, \mathrm{X} 3$, and $\mathrm{X} 4$ respectively.

Table 3. Levels of variables screened and statistical analysis results.

\begin{tabular}{|c|c|c|c|c|c|c|}
\hline Code & Variable & Low Level (-1) & High level (+1) & F-ratio & $\beta$ coeff. & p-value \\
\hline $\mathrm{X} 1$ & Methanol to Hexane ratio (\%) & 40 & 80 & 883.819 & -2.3069 & $0.0001 *$ \\
\hline $\mathrm{X} 2$ & Co-solvent to sludge ratio & 10 & 40 & 189.922 & 1.0693 & $0.0003 *$ \\
\hline $\mathrm{X} 3$ & Temperature $\left({ }^{\circ} \mathrm{C}\right)$ & 30 & 80 & 317.141 & 1.3819 & $0.0003 *$ \\
\hline $\mathrm{X} 4$ & Extraction time $(\mathrm{h})$ & 1 & 6 & 5.494 & 0.1819 & 0.0885 \\
\hline
\end{tabular}

*indicates variables with significant effects on $\mathrm{Y}_{\text {lipid }}(\mathrm{p}$-value $<0.05)$

\subsection{Process Optimization Using Steepest Ascent and Response Surface Method (RSM)}

According to the regression analysis of the screening design, the path of the steepest ascent was applied to determine the appropriate range of variables to maximize the amount of lipid extracted. The steepest ascent experiments were designed based on the maximum $\mathrm{Y}_{\text {lipid }}$ recorded during the screening step (run 6: Table 2). Accordingly, levels of significant variables were increased towards maximum lipid extraction region. A stepwise decrease in the concentration of methanol in the co-solvent mixture was performed to approach the optimal methanol to hexane ratio for the highest $\mathrm{Y}_{\text {lipid }}$ (table 4; runs from 1 -4). Similarly, a stepwise increase in the levels of solvents to sludge ratio and the temperature was carried out (Table 4; runs 5-8). From Table 4, the maximum amount of extracted lipid was obtained at methanol to hexane ratio of $40 \%$, solvent to sludge ratio of $40 \mathrm{ml} / \mathrm{g}$ scum sludge, and temperature at $90^{\circ} \mathrm{C}$. It can be clearly seen that the levels of the three variables initially screened were close to optimum.

Box-Behnken design and Response surface method (RSM) were applied to optimize and model lipid extraction yield
( $\mathrm{Y}_{\text {lipid }}$ ) using the three independent significant variables determined from the screening step (section 3.1) and numerically determined through the path of steepest ascent. Process optimization was carried out using different levels of variables and Box-Behnken design as shown in Table 5 and 6 respectively, where a multiple regression analysis was applied to the experimental data to model $\mathrm{Y}_{\text {lipid. }}$ The second order polynomial equation (Eq. 3) was used to model the correlation between the significant variables identified during the screening step, and the response variable ( $\left.\mathrm{Y}_{\text {lipid }}\right)$. The quadratic equation model for the significant variables is as follow:

Table 4. Steepest ascent experiments for maximizing lipid extraction from Scum sludge.

\begin{tabular}{lllll}
\hline Runs & $\mathbf{X 1}$ & $\mathbf{X 2}$ & $\mathbf{X 3}$ & $\mathbf{Y}_{\text {lipid }}(\mathbf{w t} / \mathbf{w t} \%)$ \\
\hline 1 & 40 & 40 & 80 & 29.33 \\
2 & 35 & 40 & 80 & 29.31 \\
3 & 30 & 40 & 80 & 29.27 \\
4 & 25 & 40 & 80 & 29.25 \\
5 & 40 & 40 & 85 & 29.34 \\
6 & 40 & 40 & 90 & 29.25 \\
7 & 40 & 50 & 80 & 29.28 \\
8 & 40 & 55 & 80 & 29.37 \\
\hline
\end{tabular}

$$
\mathrm{Y}_{\text {lipid }}=-18.312686+0.556603 \mathrm{X} 1+0.048376 \mathrm{X} 2+0.794245 \mathrm{X} 3-0.004975 \mathrm{X} 1^{2}-0.001322 \mathrm{X} 2^{2}-0.004464 \mathrm{X} 3^{2}-
$$


Table 5. Levels of variables used in the Box-Behnken design.

\begin{tabular}{lllllll}
\hline Code & Variable & Low Level (-1) & High level (+1) & Center point & F-ratio & p-value \\
\hline X1 & Methanol to Hexane ratio (\%) & 30 & 50 & 50 & 27.363 & $0.0016^{*}$ \\
X2 & Solvent to sludge ratio & 25 & 55 & 40 & 27.752 & $0.0019^{*}$ \\
X3 & Temperature $\left({ }^{\circ} \mathrm{C}\right)$ & 73 & 90 & 73 & 29.157 & $0.0217^{*}$ \\
\hline
\end{tabular}

*indicates variables with significant effects on $\mathrm{Y}_{\text {lipid }}(\mathrm{p}$-value $<0.05)$

Table 6. Box-Behnken design matrix for optimization step and the response variable ( $Y_{\text {lipid }}$ from scum sludge.

\begin{tabular}{lllll}
\hline Run order & $\mathbf{X 1}$ & $\mathbf{X 2}$ & $\mathbf{X 3}$ & $\mathbf{Y}_{\text {lipid }}(\mathbf{w t} / \mathbf{w t} \mathbf{\%})$ \\
\hline 1 & + & 0 & + & 29.3 \\
2 & 0 & - & - & 28.2 \\
3 & + & 0 & - & 28.4 \\
4 & - & 0 & - & 27.4 \\
5 & 0 & + & + & 29.4 \\
6 & - & 0 & + & 28.8 \\
7 & 0 & - & + & 28.4 \\
8 & 0 & 0 & 0 & 29.35 \\
9 & 0 & + & - & 28.7 \\
10 & 0 & 0 & 0 & 29.27 \\
11 & - & - & 0 & 27.8 \\
12 & + & + & 0 & 29.2 \\
13 & + & - & 0 & 28.6 \\
14 & 0 & 0 & 0 & 29.31 \\
15 & - & + & 0 & 28.4 \\
16 & 0 & 0 & 0 & 29.25 \\
\hline
\end{tabular}

Where, $\mathrm{Y}_{\text {lipid }}$ is the corresponding extracted lipid yield (wt/wt \%). X1, X2, X3 and X4 represents the values of methanol to hexane ratio (\%), co-solvent to sludge ratio $(\mathrm{ml} / \mathrm{g})$, and temperature $\left({ }^{\circ} \mathrm{C}\right)$ respectively.

Analysis of variance ANOVA showed that the model fit was highly significant $(p$-value $=0.0025)$ and the lack of fit was not significant $(p$-value $=0.5356)$ which shows the model represents the experimental data. The linear effect of methanol to hexane ratio (X1), temperature (X2) and solvent to sludge ratio (X3) was highly significant with $\mathrm{p}$-values $=$ $0.0016,0.0019$ and 0.0217 respectively.

Also, the quadratic effect of methanol to hexane ratio (X1) was as well highly significant $(p$-value $=0.002)$ indicating the significant effect of this factor. While the linear effect of time (X4) was insignificant ( $\mathrm{p}$-value $=0.9591$ ). The model coefficient $\left(\mathrm{R}^{2}\right)$ was found to be 0.952 , explaining $95.2 \%$ of the variability of the response variable $\left(\mathrm{Y}_{\text {lipid }}\right)$ and with the $\operatorname{AdjR}^{2}=0.88$

The maximum amount of lipid extracted was $29.4 \%$ of dried scum sludge which is lower than the results obtained by Wang et al. (2016) who claimed the extraction of $33.3 \%$ lipids to dry scum sludge using similar extraction conditions. The lower amount of lipid extracted in the current study compared with Wang et al. [32] findings can be referred to the variations in scum sludge composition based on the type of wastewater collected.

The type of collected wastewater varied from one treatment plant to another based on many different factors including 1) the origin of collected wastewater, where wastewaters from industrial origin are different in composition from domestic wastewaters; 2) The distance from the treatment plants plays a significant effect on the receiving wastewater composition since various microbial processes are taking place in sewer systems changes the wastewater chemical composition. Furthermore, the maximum lipid extraction yield ( $\left.\mathrm{Y}_{\text {lipid }}\right)$ predicted through numerically optimized conditions by the model for highest desirability (0.995) was $29.614 \%$ at methanol to hexane ratio (\%) of $42 \%$, solvent to sludge ratio (v/wt) of $51 \mathrm{ml} / \mathrm{g}$, temperature at $87 \mathrm{oC}$ (Figure 2). The threedimensional response surfaces which represents the effects of different variables on $\mathrm{Y}_{\text {lipid }}$ based on equation (4) is shown in Figure 3. The response surface indicated that maximum yield of lipid from scum sludge could be achieved by decreasing methanol to hexane ratio, increasing solvents to sludge ratio and temperature. A clear peak was observed in the response surface for variables combinations indicating optimal conditions were achieved. This would indicate the potentiality of scum sludge for biodiesel production compared with the results obtained by other studies for lipid extraction from primary and secondary sludge $[22,26,27,32]$

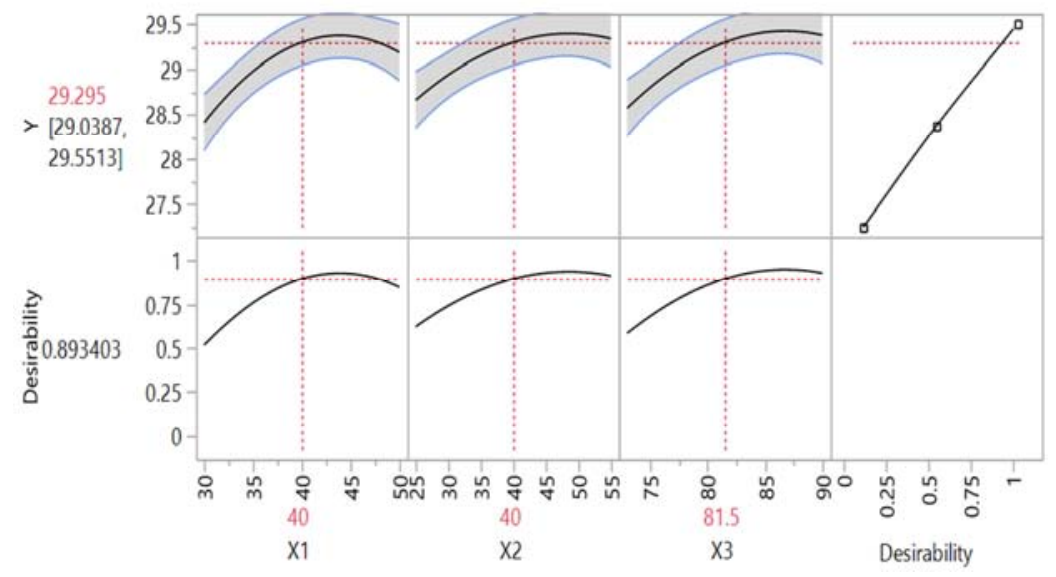

Figure 2. Prediction Profiler showing maximum desirability conditions and maximum lipid extracted (Ylipid). (X1, X2, and X3 represents the values of methanol to hexane ratio (\%), solvent to sludge ratio $(\mathrm{ml} / \mathrm{g})$, and temperature $\left({ }^{\circ} \mathrm{C}\right)$ respectively). 
$\mathbf{A}$

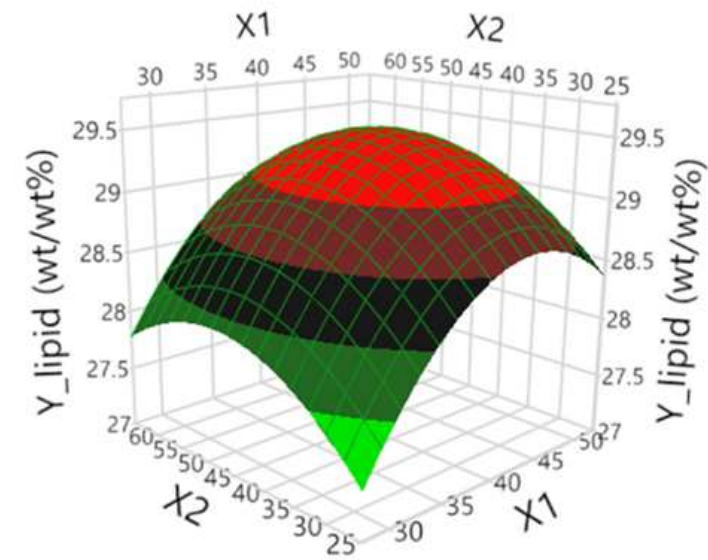

B

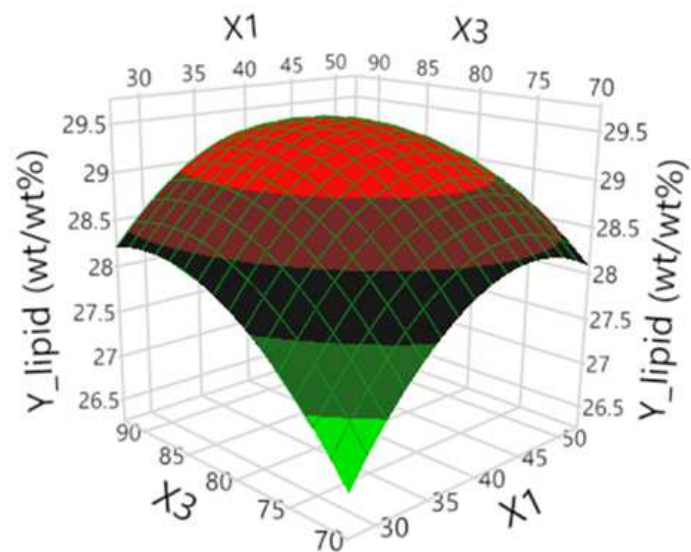

C

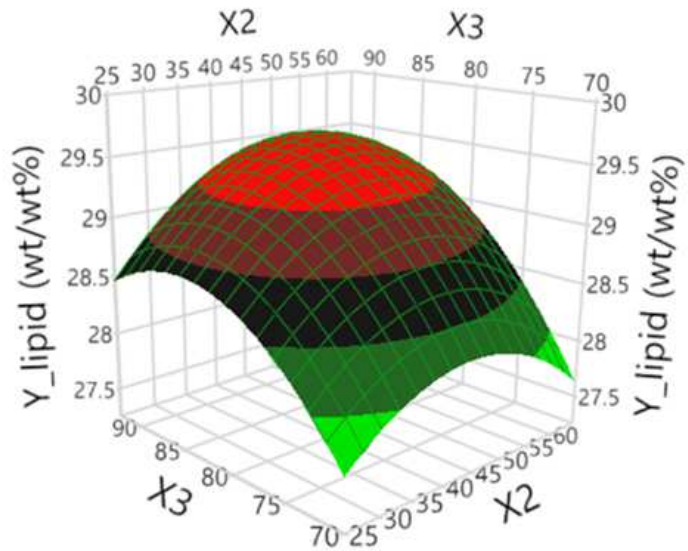

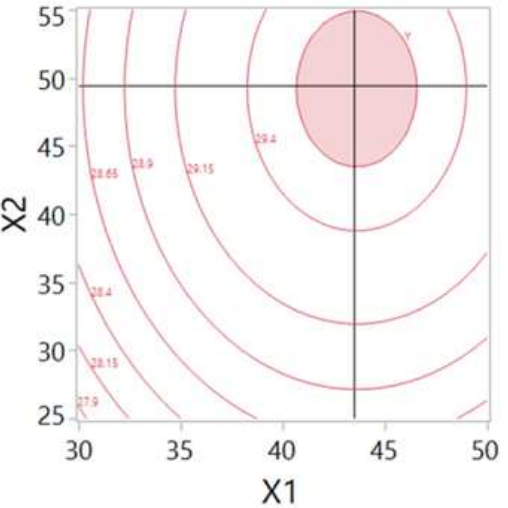
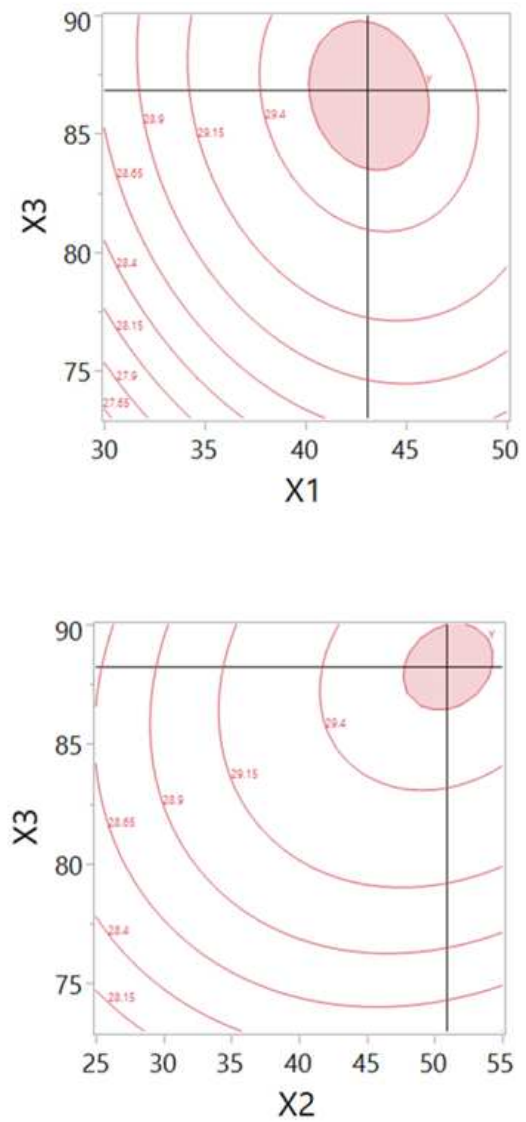

Figure 3. Three-dimension surface plot and contour plot (A-C), showing levels of variables for maximizing lipid extraction yield from scum sludge. (X1, X2, and $X 3$ represents the values of methanol to hexane ratio (\%), solvent to sludge ratio $(\mathrm{ml} / \mathrm{g})$ and temperature $\left({ }^{\circ} \mathrm{C}\right)$ respectively).

\subsection{SLs Composition of Extracted Lipid}

The FAMEs yield, which represents the SLs content of the extracted lipid, produced from ex-situ acid-catalyzed esterification/transesterification of the methanol-hexane cosolvent extracted lipid, was ranging between 7.9-9.3\% (wt/wt) based on sludge weight. These results were close to the findings reported by Wang et al.[32], who reported FAMEs yield $9.1 \%(\mathrm{wt} / \mathrm{wt})$ from scum sludge using in-situ transesterification. The fatty acid profile of FAMEs produced from the extracted lipid using acid-catalyzed ex-situ esterification/transesterification was found to be dominated by Oleic acid methyl ester (C18: 1) which represented $39.4 \%$, followed by methyl Palmitate (C16: 1) representing $24.3 \%$ of FAMEs composition (Figure 4 ).

These results were found to be in agreement with the findings reported by other researchers [30, 32]. The percentage of unsaturated and saturated fatty acids in the extracted lipid was found to be $59.3 \%$ and $40.7 \%$ respectively, which can be attributed to the relatively higher amounts of free fatty acids (FFA) in scum sludge. 


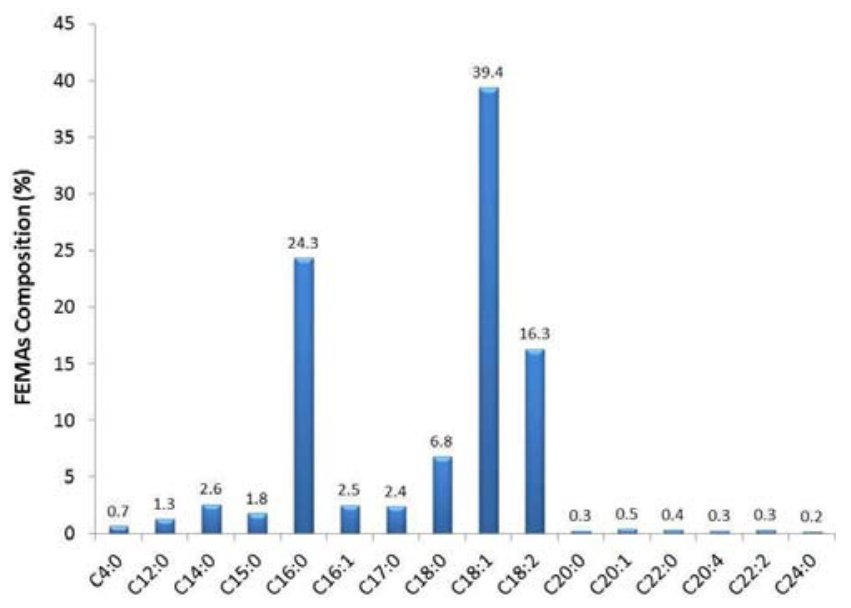

Figure 4. Fatty acid profile of FEMAs produced from scum sludge.

A correlation analysis was performed to assess the relationship between FEMAs and lipid extraction variables. The results revealed that solvent to sludge ratio $(\mathrm{ml} / \mathrm{g})$ has the highest positive significant correlation with FAMEs yield (pvalue $<0.05)$. However, methanol to hexane ratio (X1) and temperature (X3) was inversely correlated with FAMEs yield (Table 7). Hence, increasing solvent to sludge ratio would result in an increase of FAMEs (i.e. SLs), while increasing methanol to hexane ratio and temperature would reduce FAMEs yield (i.e. SLs). A similar finding was also observed by Olkiewicz et al. [26], reporting that increasing methanol concentration, temperature and extraction time resulting in the extraction of more unsaponifiable lipid (USLs) which is not convertible to FAMEs and hence reducing the overall percentage of FAMEs of extracted lipid. Accordingly, although increasing temperature would increase the lipid extraction from scum sludge, however, this increase is mainly due to the extraction of unsaponifiable lipids which are unconvertible to FEMAs. Hence, increasing the process temperature is not required for efficient lipid extraction process.

Table 7. Correlation analysis showing the relationship between FAMEs yield (\% $w t / w t)$ and lipid extraction variables X1, X2 and X3. (Numbers refers to runs order in Table 4).

\begin{tabular}{|c|c|c|c|c|}
\hline Variables & X1: methanol to hexane ratio & X2: solvent to sludge ratio & X3: temperature & FEMAs (wt/wt\%) \\
\hline $\mathrm{X} 1$ : methanol to hexane ratio & 1 & 0.387 & 0.371 & -0.552 \\
\hline $\mathrm{X} 2$ : solvent to sludge ratio & 0.387 & 1 & -0.303 & 0.661 \\
\hline X3: temperature & 0.371 & -0.303 & 1 & -0.259 \\
\hline
\end{tabular}

Bold numbers indicates variables with significant correlations ( $\mathrm{p}$-value $<0.05$ )

\section{Conclusion}

The results presented in the current study revealed the potentiality of scum sludge as a feedstock for biodiesel production. The highest amount of extracted lipids (29.4\% wt lipid/wt sludge) was achieved using 40: 40: 90: 6 independent variables conditions (methanol to hexane ratio, solvent to sludge ratio, temperature and extraction time respectively). The optimization process led to an increase in lipid extraction yield by $1.5 \%$ compared with the highest results recorded in the screening experiments. This small increase can only be justified by that the selected ranges of variables used in the screening experiments were close to the optimum. The amount of lipid extracted in the current study was higher in comparison with previous records from primary and secondary sludge confirming the suitability of using scum sludge as an alternative feedstock for biodiesel production. Also, the results have revealed that the yield of lipid extraction increases significantly with reducing methanol to hexane ratio while increasing solvent amount and the temperature of the extraction process. Reducing methanol of hexane ratio results in higher lipid yield indicating that the neutral nature of lipids dominating scum sludge. However, increasing temperature resulted in a reduction in FEMAs produced, confirming the need to consider the saponifiable lipid fraction of the extracted lipid. This observation can reduce the biodiesel production cost from scum sludge significantly. And it will be more convenient to optimize SLs extraction rather than focusing on total lipid extraction. Also, the study has demonstrated the usefulness of applying Response Surface Method (RSM) approach for optimizing lipid extraction process variables and was applied successfully in the current study. To our knowledge, the current study is among the fewest results reported so far for optimizing lipid extraction conditions from scum sludge and reflected the importance of considering SLs for feedstocks assessments as a source for biodiesel production.

\section{References}

[1] Morsy, Fatthy Mohamed, and Samir Hag Ibrahim. 2016. Concomitant hydrolysis of sucrose by the long half-life time yeast invertase and hydrogen production by the hydrogen overproducing Escherichia coli HD701. Energy 109: $412-$ 419. doi: $10.1016 /$ j.energy.2016.05.006.

[2] Morsy, Fatthy Mohamed, Ismail Ahmed Ismail, and Samir Hag Ibrahim. 2016. A cost-effective, temperature dependent, control of $\mathrm{H} 2$ production period by Escherichia coli and using waste culture to detoxify the carcinogenic $\mathrm{Cr} 6 \mathrm{p}$. International Journal of Hydrogen Energy 41: 22775-22785. doi: 10.1016/j.ijhydene.2016.10.085.

[3] Atabani, A. E., A. S. Silitonga, Irfan Anjum Badruddin, T. M. I. Mahlia, H. H. Masjuki, and S. Mekhilef. 2012. A comprehensive review on biodiesel as an alternative energy resource and its characteristics. Renewable and Sustainable Energy Reviews 16: 2070 - 2093. doi: 10.1016/j.rser.2012.01.003. 
[4] Dufreche, Stephen, R. Hernandez, T. French, D. Sparks, M. Zappi, and E. Alley. 2007. Extraction of lipids from municipal wastewater plant microorganisms for production of biodiesel. JAOCS, Journal of the American Oil Chemists' Society 84: 181 - 187. doi: 10.1007/s11746-006-1022-4.

[5] Leiva-Candia, D. E., S. Tsakona, N. Kopsahelis, I. L. Garcia, S. Papanikolaou, M. P. Dorado, and A. A. Koutinas. 2015. Biorefining of by-product streams from sunflower-based biodiesel production plants for integrated synthesis of microbial oil and value-added co-products. Bioresource Technology 190: 57 - 65 . doi: 10.1016/j.biortech.2015.03.114.

[6] Leiva-Candia, D. E., S. Tsakona, N. Kopsahelis, I. L. Garcia, S. Papanikolaou, M. P. Dorado, and A. A. Koutinas. 2014. The potential for agro-industrial waste utilization using oleaginous yeast for the production of biodiesel. Bioresource Technology 123: 33 - 42. doi: http://dx.doi.org/10.1016/j.fuel.2014.01.054.

[7] Banković-Ilić, Ivana B., Ivan J. Stojković, Olivera S. Stamenkovi ć, Vlada B. Veljkovic, and Yung Tse Hung. 2014. Waste animal fats as feedstocks for biodiesel production. Renewable and Sustainable Energy Reviews 32: $238-254$. doi: 10.1016/j.rser.2014.01.038.

[8] Bharathiraja, B., M. Chakravarthy, R. Ranjith Kumar, D. Yuvaraj, J. Jayamuthunagai, R. Praveen Kumar, and S. Palani. 2014. Biodiesel production using chemical and biological methods - A review of process, catalyst, acyl acceptor, source and process variables. Renewable and Sustainable Energy Reviews 38: 368 - 382. doi: 10.1016/j.rser.2014.05.084.

[9] Ingole, S P, and A U Kakde. 2012. Evaluation of various plant species for biodiesel production. Current Botany 3: $22-25$.

[10] Knothe, Gerhard. 2010. Biodiesel and renewable diesel: A comparison. Progress in Energy and Combustion Science 36: 364 - 373. doi: 10.1016/j.pecs.2009.11.004.

[11] Leung, Dennis Y. C., Xuan Wu, and M. K. H. Leung. 2010. A review on biodiesel production using catalyzed transesterification. Applied Energy 87: 1083-1095. doi: 10.1016/j.apenergy.2009.10.006.

[12] Demirbas, Ayhan. 2009. Progress and recent trends in biodiesel fuels. Energy Conversion and Management 50: 14 34. doi: 10.1016/j.enconman.2008.09.001.

[13] Krawczyk, Tom. 1996. Biodiesel. Alternative fuel makes inroads but hurdles remain. Inform 7: $800-815$.

[14] Balat, Mustafa. 2011. Potential alternatives to edible oils for biodiesel production - A review of current work. Energy Conversion and Management 52: 1479-1492. doi: 10.1016/j.enconman.2010.10.011.

[15] Bharathiraja, B, D Yogendran, R Ranjith Kumar, M Chakravarthy, and S Palani. 2014. Biofuels from sewage sludge-A review. International Journal of ChemTech Research 6: $974-4290$.

[16] Kargbo, Dm. 2010. Biodiesel production from municipal sewage sludges. Energy \& Fuels 24: $2791-2794$. doi: 10.1021/ef1001106.

[17] Olkiewicz, Magdalena Anna. 2015. Production of Biodiesel From Sludge Generated in Municipal Sludge Generated in Municipal (Thesis). Rovira i Virgili University.

[18] Revellame, Emmanuel, Rafael Hernandez, William French, William Holmes, Earl Alley, and Robert Callahan. 2011.
Production of biodiesel from wet activated sludge. Journal of Chemical Technology and Biotechnology 86: 61-68. doi: $10.1002 /$ jctb. 2491 .

[19] Sheik, Abdul R., Emilie E. L. Muller, and Paul Wilmes. 2014. A hundred years of activated sludge: time for a rethink. Frontiers in Microbiology 5. Frontiers: 47. doi: 10.3389/fmicb.2014.00047.

[20] Kargbo, David M. 2010. Biodiesel Production from Municipal Sewage Sludges. Energy \& Fuels 24. American Chemical Society: 2791 - 2794. doi: 10.1021/ef1001106.

[21] Mondala, Andro, Kaiwen Liang, Hossein Toghiani, Rafael Hernandez, and Todd French. 2009. Biodiesel production by in situ transesterification of municipal primary and secondary sludges. Bioresource Technology 100: $1203-1210$. doi: 10.1016/j.biortech.2008.08.020.

[22] Pokoo-Aikins, Grace, Aubrey Heath, Ray A. Mentzer, M. Sam Mannan, William J. Rogers, and Mahmoud M. El-Halwagi. 2010. A multi-criteria approach to screening alternatives for converting sewage sludge to biodiesel. Journal of Loss Prevention in the Process Industries 23: $412-420$. doi: 10.1016/j.jlp.2010.01.005.

[23] Boocock, David G. B., Samir K. Konar, Anna Leung, and Lang D. Ly. 1992. Fuels and chemicals from sewage sludge. Fuel 71: 1283 - 1289. doi: 10.1016/0016-2361(92)90055-S.

[24] Siddiquee, Muhammad N., and Sohrab Rohani. 2011. Experimental analysis of lipid extraction and biodiesel production from wastewater sludge. Fuel Processing Technology 92: 2241 - 2251. doi: 10.1016/j.fuproc.2011.07.018.

[25] Siddiquee, Muhammad N., and Sohrab Rohani. 2011. Lipid extraction and biodiesel production from municipal sewage sludges: A review. Renewable and Sustainable Energy Reviews 15: 1067 - 1072.

[26] Girisha, Sirangala Thimappa, Krishnappa Ravikumar, and Venkatachalapathy Girish. 2014. Lipid extraction for biodiesel production from municipal sewage water sludge. European Journal of Experimental Biology 4: 242 - 249.

[27] Mondala, Andro, Kaiwen Liang, Hossein Toghiani, Rafael Hernandez, and Todd French. 2009. Biodiesel production by in situ transesterification of municipal primary and secondary sludges. Bioresource Technology 100: $1203-1210$. doi: 10.1016/j.biortech.2008.08.020.

[28] Pastore, Carlo, Antonio Lopez, Vincenzo Lotito, and Giuseppe Mascolo. 2013. Biodiesel from dewatered wastewater sludge: A two-step process for a more advantageous production.

Chemosphere 92: 667 - 673. doi: 10.1016/j.chemosphere.2013.03.046.

[29] Olkiewicz, Magdalena, Natalia V. Plechkova, Azael Fabregat, Frank Stiiber, Agustí Fortuny, Josep Font, and Christophe Bengoa. 2015. Efficient extraction of lipids from primary sewage sludge using ionic liquids for biodiesel production. Separation and Purification Technology 153: 118 - 125. doi: 10.1016/j.seppur.2015.08.038.

[30] Olkiewicz, Magdalena, Martin Pablo Caporgno, Agustí Fortuny, Frank Stiuber, Azael Fabregat, Josep Font, and Christophe Bengoa. 2014. Direct liquid-liquid extraction of lipid from municipal sewage sludge for biodiesel production. Fuel Processing Technology 128: 331 - 338. doi: 10.1016/j.fuproc.2014.07.041. 
[31] Qi, Juanjuan, Fenfen Zhu, Xiang Wei, Luyao Zhao, Yiqun Xiong, Xuemin Wu, and Fawei Yan. 2015. Comparison of biodiesel production from sewage sludge obtained from the $\mathrm{A} 2 / \mathrm{O}$ and MBR processes by in situ transesterification. Waste Management 49: 212 - 220. doi: 10.1016/j.wasman.2016.01.029.

[32] Kumar, Manish, Pooja Ghosh, Khushboo Khosla, and Indu Shekhar Thakur. 2016. Biodiesel production from municipal secondary sludge. Bioresource Technology 216: $165-171$. doi: 10.1016/j.biortech.2016.05.078.

[33] Bi, Chong hao, Min Min, Yong Nie, Qing long Xie, Qian Lu, Xiang yuan Deng, Erik Anderson, Dong Li, Paul Chen, and Roger Ruan. 2015. Process development for scum to biodiesel conversion. Bioresource Technology 185: $185-193$. doi: 10.1016/j.biortech.2015.01.081.

[34] di Bitonto, Luigi, Antonio Lopez, Giuseppe Mascolo, Giuseppe Mininni, and Carlo Pastore. 2016. Efficient solventless separation of lipids from municipal wet sewage scum and their sustainable conversion into biodiesel. Renewable Energy 90: 55 - 61. doi: 10.1016/j.renene.2015.12.049.

[35] Wang, Yi, Sha Feng, Xiaojuan Bai, Jingchan Zhao, and Siqing Xia. 2016. Scum sludge as a potential feedstock for biodiesel production from wastewater treatment plants. Waste Management 47: 91 - 97. doi: 10.1016/j.wasman.2015.06.036.

[36] Chipasa, K. B., and K. Mędrzycka. 2006. Behavior of lipids in biological wastewater treatment processes. Journal of Industrial Microbiology \& Biotechnology 33: 635 - 645. doi: 10.1007/s10295-006-0099-y.

[37] Wiltsee, George. 1998. Waste grease resource in 30 US metropolitan areas. In The Proceedings of Bioenergy 98 Conference, Wisconsin, $956-963$.
[38] Imandi, Sarat Babu, Veera Venkata Ratnam Bandaru, Subba Rao Somalanka, Sita Ramalakshmi Bandaru, and Hanumantha Rao Garapati. 2008. Application of statistical experimental designs for the optimization of medium constituents for the production of citric acid from pineapple waste. Bioresource Technology 99: 4445 - 4450. doi: 10.1016/j.biortech.2007.08.071.

[39] Long, Chuannan, Jingjing Cui, Zuotao Liu, Yuntao Liu, Minnan Long, and Zhong Hu. 2010. Statistical optimization of fermentative hydrogen production from xylose by newly isolated Enterobacter sp. CN1. International Journal of Hydrogen Energy 35: 6657 - 6664. doi: 10.1016/j.ijhydene.2010.04.094.

[40] Annadurai, G., S. Mathalai Balan, and T. Murugesan. 1999. Box-Behnken design in the development of optimized complex medium for phenol degradation using Pseudomonas putida (NICM 2174). Bioprocess Engineering 21. SpringerVerlag: 415 - 421. doi: 10.1007/PL00009082.

[41] Francis, Febe, Abdulhameed Sabu, K. Madhavan Nampoothiri, Sumitra Ramachandran, Sanjoy Ghosh, George Szakacs, and Ashok Pandey. 2003. Use of response surface methodology for optimizing process parameters for the production of $\alpha$-amylase by Aspergillus oryzae. Biochemical Engineering Journal 15: $107-115$. doi: 10.1016/S1369703X(02)00192-4.

[42] Varrone, Cristiano, Barbara Giussani, Giulio Izzo, Giulia Massini, Antonella Marone, Antonella Signorini, and Aijie Wang. 2012. Statistical optimization of biohydrogen and ethanol production from crude glycerol by microbial mixed culture. International Journal of Hydrogen Energy 37: 16479 - 16488. doi: 10.1016/j.ijhydene.2012.02.106. 